\title{
Clinical Implications and ESHRE/ESGE Classification of Mullerian Anomalies: A Case Series

\author{
Uma Gupta ${ }^{1}$, Vartika Tripathi ${ }^{2 *}$ and Priya Sharma ${ }^{3}$
}

${ }_{1}^{1}$ Professor and Head, Department of Obstetrics and Gynaecology, Mayo Institute of Medical Sciences, Uttar Pradesh, India ${ }^{2}$ Assistant Professor, Department of Obstetrics and Gynaecology, Mayo Institute of Medical Sciences, Uttar Pradesh, India ${ }^{3}$ Associate Professor, Department of Obstetrics and Gynaecology, Mayo Institute of Medical Sciences, Uttar Pradesh, India

${ }^{*}$ Corresponding author: Vartika Tripathi, Assistant Professor, Department of Obstetrics and Gynaecology, Mayo Institute of Medical Sciences, Uttar Pradesh, India, Tel: 9621086291

\begin{abstract}
Mullerian or paramesonephric ducts form the female genital tract and any deviation from the normal can lead to Mullerian anomalies. Depending on the type of Mullerian anomaly; the presentations, required investigations and treatment options vary considerably and so does the counseling regarding the condition. Due to the highly varied profile of patients with Mullerian anomalies, a number of classification systems have been proposed to aid in their diagnosis and management. A thorough knowledge of the development of female genital tract and its associated anomalies is necessary to diagnose these disorders and an adequate workup is imperative before planning the treatment. This case series comprises of 17 cases of Mullerian anomalies, diagnosed through clinical history, physical examination, radiological scans or surgery. The case series is multiparametric in design and focuses on multiple parameters of an individual case. Through the present case series we aim to evaluate the various clinical presentations of the Mullerian duct anomalies, classify them as per ESHRE classification system, assess the other congenital anomalies associated with them and also study the optimum mode of management used for the respective cases.
\end{abstract}

\section{Introduction}

Mullerian or paramesonephric ducts form the female genital tract and any deviation from the normal can lead to Mullerian anomalies. These anomalies represent a rather common benign condition with prevalence being $6.7 \%$ in the general population, $7.3 \%$ in the infertile population and $16.7 \%$ in recurrent miscarriage population [1]. The prevalence of various Mullerian anomalies is re- ported to be as follows [2]: Arcuate- 20\%; Septate- 35\%; Bicornuate Uterus- 25\%; Unicornuate- 10\%; Didephic$8 \%$ and others- $3 \%$. Depending on the type of Mullerian anomaly; the presentations, required investigations and treatment options vary considerably and so does the counseling regarding the condition. Due to the highly varied profile of patients with Mullerian anomalies, a number of classification systems have been proposed to aid in their diagnosis and management. The European society of human reproduction and embryology (ESH$\mathrm{RE}$ ) and the European society for gynaecological endoscopy (ESGE) have developed a system of classification in 2013 - Congenital uterine anomalies (CONUTA) for a more effective way of classifying and managing mullerian anomalies [3].

A thorough knowledge of the development of female genital tract and its associated anomalies is necessary to diagnose these disorders and an adequate workup is imperative before planning the treatment. This case series comprises of 17 cases of Mullerian anomalies, diagnosed through clinical history, physical examination, radiological scans or surgery. The case series is multiparametric in design and focuses on multiple parameters of an individual case. Parameters like age, clinical presentation, hormonal profile, Ultrasonography (USG), Magnetic resonance imaging (MRI), Computed tomography (CT) scan, IVP (Intravenous pyelogram) findings \& mode of treatment were analyzed. Through the present case series we aim to evaluate the various clinical

Citation: Gupta U, Tripathi V, Sharma P (2021) Clinical Implications and ESHRE/ESGE Classification of Mullerian Anomalies: A Case Series. Obstet Gynecol Cases Rev 8:191. doi.org/10.23937/23779004/1410191

Accepted: February 08, 2021: Published: February 10, 2021

Copyright: (c) 2021 Gupta U, et al. This is an open-access article distributed under the terms of the Creative Commons Attribution License, which permits unrestricted use, distribution, and reproduction in any medium, provided the original author and source are credited. 
presentations of the Mullerian duct anomalies, classify them as per ESHRE classification system, assess the other congenital anomalies associated with them and also study the optimum mode of management used for the respective cases.

\section{Case Descriptions}

\section{Case 1}

A 15-year-old girl presented as a case of primary amenorrhoea. On examination her secondary sexual characteristics were found to be well developed. Uterus was 14 weeks size, mobile firm and non tender. Local examination revealed a thick transverse septum while on per rectal examination uterus, along with a mass in right fornix, could be palpated. USG and MRI findings confirmed hematocolpos, hematometra and transverse vaginal septum. She was taken up for laparotomy with vaginoplasty. Per operatively a high up transverse septum was resected followed by drainage of the collected fluid. On opening the abdomen hemi uterus with right cornua not communicating with cavity was discovered. An incision was given over right cornua to drain the fluid followed by cornual resection. Serial dilatation by $\mathrm{He}-$ gar's dilators followed by vaginal moulds insertion was done.

\section{Case 2}

A 17-year-old girl who presented with primary amenorrhoea, had well developed secondary sexual characteristics on examination. Abdomen was soft, with no palpable mass and local examination revealed a blind vagina. No masses suggestive of uterus could be palpated on per rectal examination. Her hormone status was unremarkable. However on USG, right sided ectopic malrotated kidney with absent uterus and tubes-mullerain agenesis were found. IVP (Figure 1) and contrast

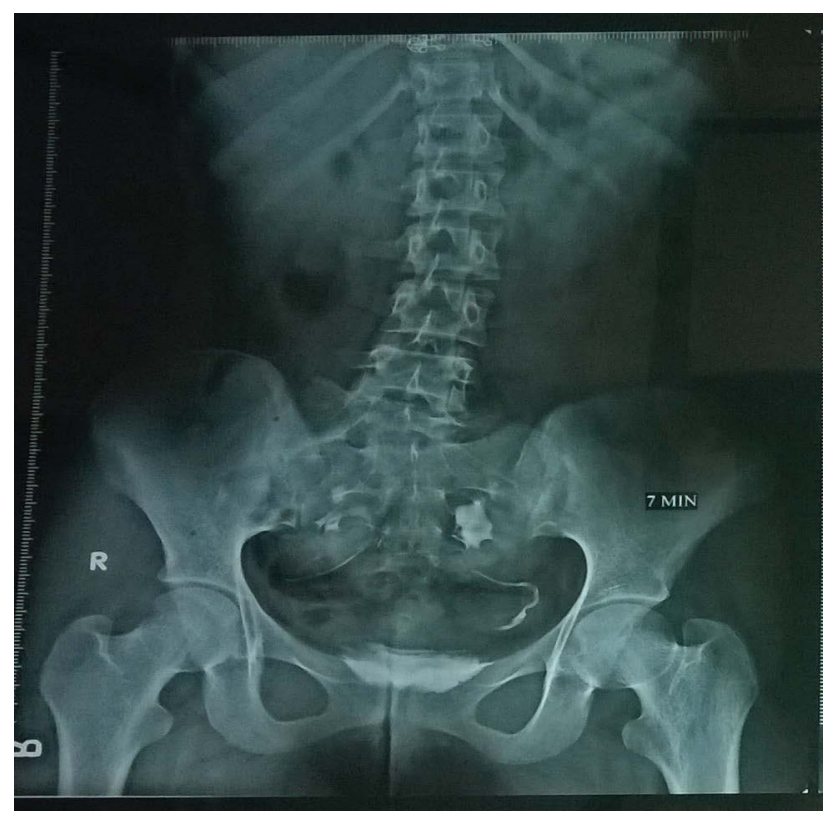

Figure 1: IVP showing solitary ectopic pelvic kidney. enhanced CT abdomen confirmed a solitary ectopic pelvic kidney, non-visualized uterus consistent with Meyer rokitansky kuster hauser (MRKH) syndrome. Patient was counselled for vaginoplasty.

\section{Case 3}

A 28-year-old nulliparous female, married for 7 years came with complaints of lower abdominal pain for 7-10 days. She also gave history of dysmenorrhoea, and oligomenorrhoea since 6 years. Eight years back patient had complaints of primary amenorrhoea for which she had undergone vaginoplasty with skin graft. She had undergone repeated cervical dilatations, following which she started having menses. Per abdominally a mass of 12-14 weeks was palpable in the suprapubic region with restricted mobility, vague tenderness and variegated consistency. On per speculum examination skin grafted vagina, with fibrosed tough vault was visualized. USG showed that the uterus was $8.2 \times 4.5 \times 5.5 \mathrm{~cm}$ with 14 $\mathrm{mm}$ thick endometrium. Both ovaries were not visualized separately. Fluid collection of $180 \mathrm{cc}$ in left side of uterus and in right iliac fossa measuring $90 \mathrm{~mm} \times 90$ $\mathrm{mm} \times 92 \mathrm{~mm}$ visualized with gut loops adherent within the fluid. There was also evidence of fluid in the pouch of Douglas. Patient underwent laparotomy. Per operatively uterus was found to be of 12 weeks size, left hydrosalphinx and adherent ovarian cyst. Right ovary was adherent to uterus \& bowel with chocolate cyst. There was evidence of extensive endometriosis. Subtotal hysterectomy with bilateral salpingoopherectomy was done. Histopathology report confirmed myohyperplasia with predominant fibrous elements, Cystic glandular hyperplasia and bilateral ovarian endometriosis. Postoperatively patient was given Leuprolide acetate $3.75 \mathrm{mg}$ subcutaneously every month for three doses followed by hormone replacement therapy (Figure 2).

\section{Case 4}

A 35-year-old nulliparous female presented with complaints of lower abdominal pain and dysparuenia of 3-4 months duration. She had not attained menarche and her marital stay was 2 years. On examination a mobile and firm mass of 14-16 weeks was palpable in suprapubic region. She has a 2 inches long blind vagina. Per vaginally a mass of 16 weeks size arising from the vagina could be palpated and per rectal findings were also consistent with it. USG showed a bulky uterus with a collection of $180 \mathrm{cc}$ in vagina. IVP done was within normal limits. A diagnosis of high transverse vaginal septum with haematometra and haematocolpos was made. Per operatively a cruciate incision was given on septum with drainage of about $150 \mathrm{ml}$ of collection. Cervical Os was not seen; instead a small dimple was visualized. A probe was inserted, followed by Hegar's dilator and around 20 $\mathrm{ml}$ collection from the uterus was aspirated. Mallecot's catheter was inserted and fixed in the tract thus created. Vaginal mould was inserted and patient instructed to use it regularly (Figure 3). 


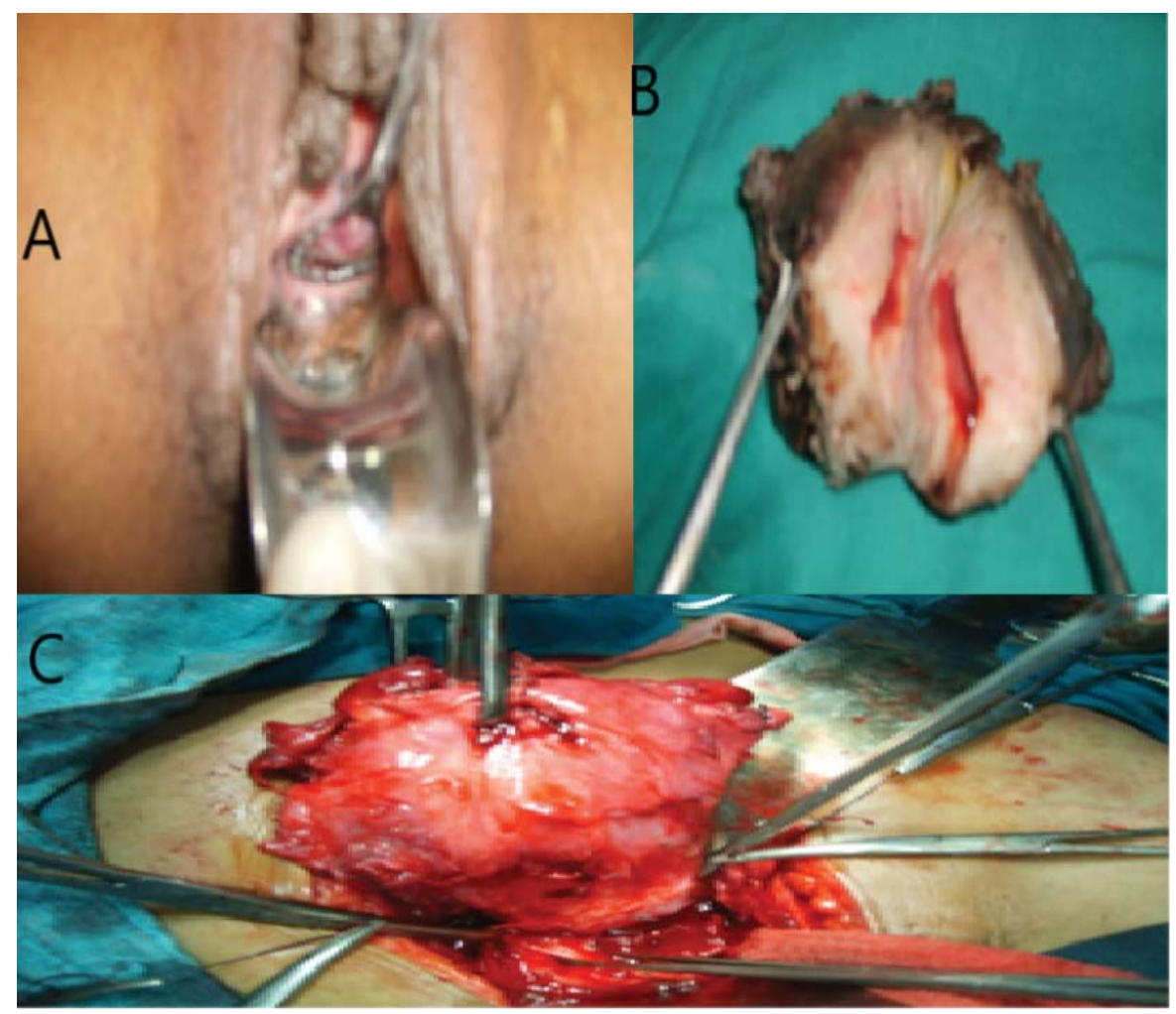

Figure 2: A) Per speculum examination showing skin grafted vagina; B) Uterus showing myohyperplasia; C) Peroperative; Uterus with multiple adhesions.

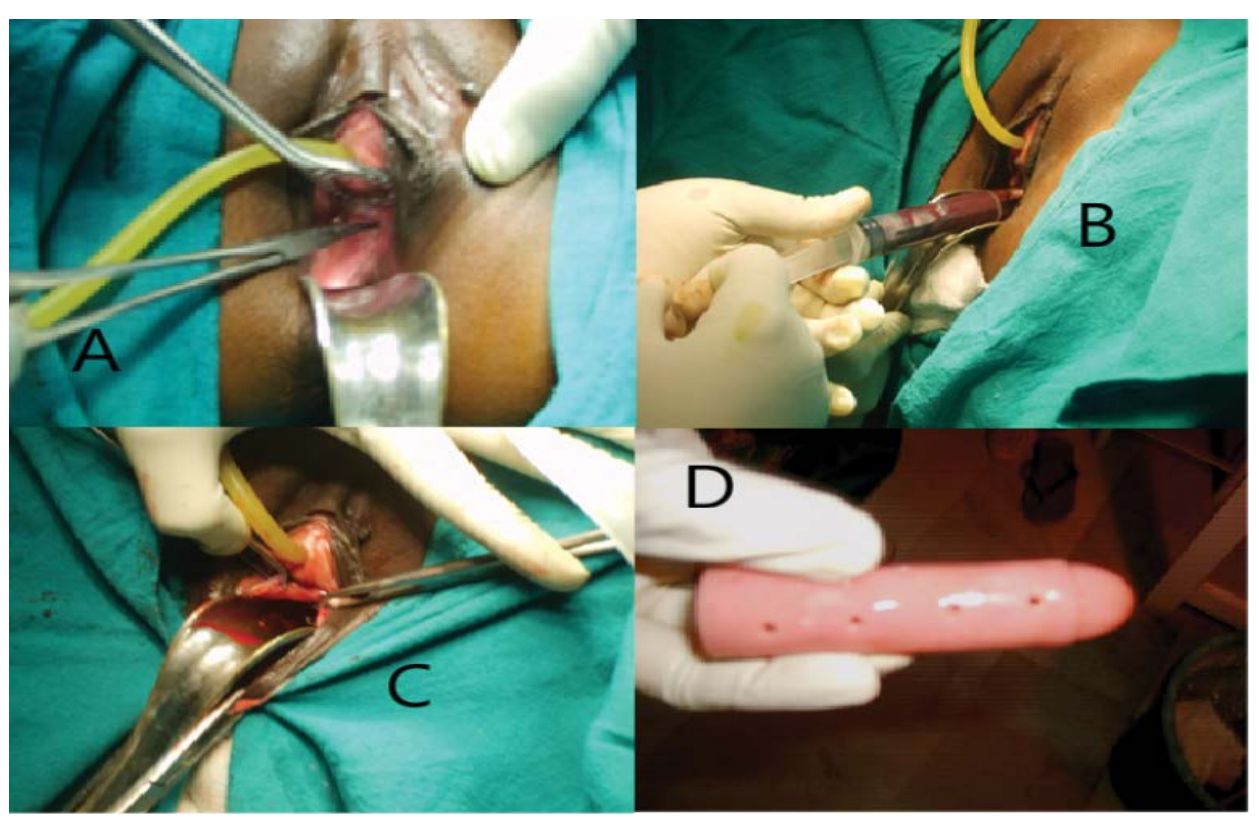

Figure 3: A) Per speculum examination showing blind vagina; B) Chocolate like material being aspirated from the hematocolpos; C) Excision of vaginal septum; D) Vaginal mould.

\section{Case 5}

A 21-year-old nulliparous female, a case of primary amenorrhoea was found to have well developed secondary sexual characteristics. Her per abdominal examination was unremarkable, however she was found to have a blind vagina with a vaginal length of $3 \mathrm{~cm}$ on further examination Per rectally uterus and cervix could not be felt. A transverse band could be palpated. USG revealed a rudimentary uterus $(24.6 \times 10.3 \times 16.7 \mathrm{~mm})$ and normal bilateral adnexa. Diagnostic laparoscopy was done and per operatively bilateral ovaries and tubes were found to be present but the uterus could not be visualized.

\section{Case 6}

A 17-year-old female presented with complaints of heavy menstrual bleeding since menarche. Per abdominal examination was unremarkable and per speculum/ 


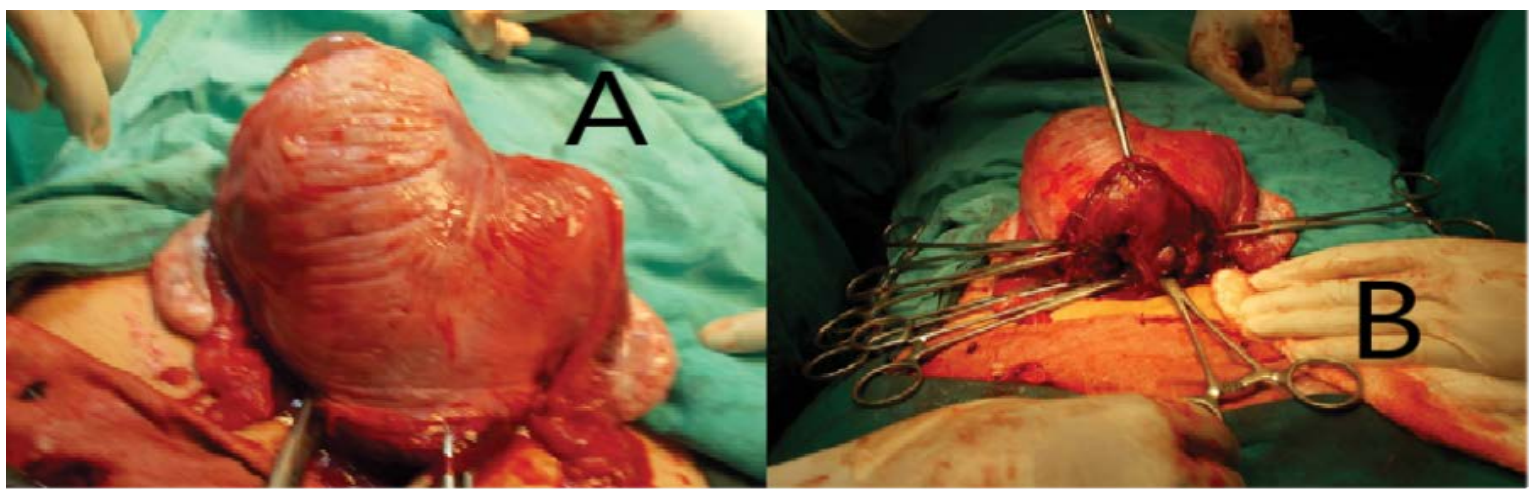

Figure 4: A) Sub-septate uterus; B) Septa.

per vaginal examination was not done. On per rectal examination 2 separate masses were felt. However on USG patient was found to have uterus didelphys. She was treated symptomatically and counseled regarding evaluation to rule out other associated anomalies, but the patient did not come for follow up.

\section{Case 7}

A 24-year-old female presented as a case of primary infertility. Examination findings and all investigations done for the evaluation of infertility were within normal limits. On USG she was discovered to have a uterine septum. She was taken up for hysteroscopy, where she was found to have a partial septate uterus and subsequently septoplasty was done. The patient is being followed up.

\section{Case 8}

A 15-year-old girl presented with primary amenorrhoea. She had well developed secondary sexual characteristics on examination. Abdomen was soft, with no palpable mass and local examination revealed a blind vagina. No masses suggestive of uterus could be palpated on per rectal examination. Her hormone status was unremarkable. USG revealed absent uterus and tubes-mullerain agenesis. MRI confirmed MRKH syndrome with no other associated anomalies. Patient counselled for vaginoplasty.

\section{Case 9}

A 56-year-old post menopausal female came with complaints of 2 episodes of bleeding per vaginum. No other significant past history or examination findings were found. Her evaluation for cancer cervix and cancer endometrium was unremarkable. When she did not respond to medical management, she was planned for hysterectomy. Per operatively left unicornuate uterus with absent right horn was found.

\section{Case 10}

A 22-year-old female presented as a case of primary infertility. Examination findings and all investigations done for the evaluation of infertility were within normal limits. On USG she was discovered to have a uterine septum. She was taken up for hysteroscopy, where she was found to have a complete septate uterus and subsequently septoplasty was done. The patient was lost to follow up.

\section{Case 11}

A 13-year-old girl presented with acute pain abdomen. She had attained menarche 1 year back and had her last menstrual period 6 weeks back. On examination a suprapubic lump of 22 weeks size was felt. It was bilobed, firm in consistency, non-tender and more on the right side. The same mass was felt vaginally, it was cystic, smooth, non-tender, and in direct communication with a bulge seen on the right side of the vagina. USG showed hematocolpos with hematometra. She was taken up for examination under anaesthesia. Old vaginal blood was aspirated followed by formation of a long window by excising a portion of the thick septum on the right side. Right sided cervical os was visible through the window. A final diagnosis of obstructed uterus bicornis bicollis with septate vagina was made.

\section{Case 12}

24-year-old $\mathrm{G}_{2} \mathrm{P}_{0}+1 \mathrm{~L}_{0}$ with 35 weeks 4 day pregnancy, presented at term with complaints of decreased fetal movement since 1 day. On examination fundal height was around 34 weeks, longitudinal lie, breech presentation, mild uterine contractions and fetal heart rate of 130 beats per minute. USG showed a Single live intra-uterine fetus (SLIUF) of 33 Weeks 2 Days gestation with breech presentation, severe oligohydramnios with posterior, upper uterine segment, grade II placenta and no obvious congenital anomaly. Patient underwent Lower segment caesarean section (LSCS). Per operatively the fetus was found to be in one horn and placenta in other with subseptate uterus and single cervix (Figure 4).

\section{Case 13}

A primigravida with 16 weeks pregnancy came with complaints of acute pain abdomen. Her blood investigations were within normal limits however the USG showed ruptured ectopic pregnancy with fetus lying in the abdomen. She underwent laparotomy and per operatively a macerated fetus was found in the abdominal 
cavity, with a bicornuate uterus and ruptured cornua of left horn. Placenta was adhered to the cornua. Subsequently cornual resection was done following removal of the fetus.

\section{Case 14}

A 25 -year-old primigravida at 27 weeks 4 days of gestation came with uncontrollable bleeding per vaginum with central placenta previa (grade iv) with oligohydramnios. On examination her fundal height was 28 weeks with cephalic presentation and a fetal heart rate of 126 beats per minute. USG finding showed SLIUF of 22 weeks pregnancy with placenta completely covering the os with reduced liquor, and no congenital anomaly in the fetus. She underwent emergency surgery and per operatively a unicornuate uterus was present. Placenta seen anterior, adhered to upper and lower uterine segment and was delivered in bits. Baby delivered through placenta.

\section{Case 15}

A 26-year-old female, $G_{2} P 1 L_{0}$ with 7 months period of gestation presented with complaints of leaking per vaginum since 18 hours. She gave history of previous preterm vaginal delivery at 30 weeks of gestation, 7 months back. Baby expired immediately after birth. On examination she had a fundal height of 24 weeks with oblique lie and breech presentation. Fetal heart rate was 150 beats per minute. USG showed a SLIUF with nil liquor. Patient was taken up for caesarean section in view of anhydraminos. Per operatively right sided unicornuate uterus with absent left horn with normal tubes \& ovary was seen.

\section{Case 16}

A 26-year-old $G_{1} P_{0} L_{0}$ with 37 weeks 6 days pregnancy, presented at term with complaints of pain abdomen since 1 day. On examination fundal height was full term, oblique lie, with moderate uterine contractions and fetal heart rate of 138 beats per minute. USG showed SLIUF of 37 weeks 2 days gestation with oblique lie and no obvious congenital anomaly. Patient underwent Lower segment caesarean section (LSCS). Per operatively a

Table 1: The clinical picture, associated Mullerian anomaly and subsequent management of the respective cases.

\begin{tabular}{|c|c|c|c|c|}
\hline \multicolumn{5}{|c|}{ Gynaecology Cases } \\
\hline Case & Clinical Picture & Anamoly & Management & $\begin{array}{l}\text { ESHRE } \\
\text { Classification }\end{array}$ \\
\hline Case 1 & Primary Amenorrhea & $\begin{array}{l}\text { Hemi Uterus with right non- } \\
\text { communicating horn with } \\
\text { transverse vaginal septum }\end{array}$ & $\begin{array}{l}\text { Cornual resection with } \\
\text { transverse vaginal septal } \\
\text { resection }\end{array}$ & U4a CoV3 \\
\hline Case 2 & Primary Amenorrhea & $\begin{array}{l}\text { Absent Uterus and Tubes } \\
\text { with Solitary Ectopic Pelvic } \\
\text { Kidney (MRKH) }\end{array}$ & $\begin{array}{l}\text { Conservative (planned for } \\
\text { vaginoplasty) }\end{array}$ & U5 C4 V4 \\
\hline Case 3 & $\begin{array}{l}\text { Primary Amenorrhoea with } \\
\text { Pelvic Endometriosis }\end{array}$ & Cervical Atresia & $\begin{array}{l}\text { Subtotal Hysterectomy } \\
\text { with Bilateral Salphingo } \\
\text { Opherectomy }\end{array}$ & U0 C4 V0 \\
\hline Case 4 & Primary Amenorrhoea & Transverse Vaginal Septum & $\begin{array}{l}\text { Septal resection with } \\
\text { Vaginoplasty }\end{array}$ & U0 C0 V3 \\
\hline Case 5 & Primary Infertility & Absent Uterus & Conservative & U5 C4 V3 \\
\hline Case 6 & Abnormal Uterine Bleeding & Uterus Didelphys & Loss to follow up & U3c C2 V1 \\
\hline Case 7 & Primary Infertility & Septate Uterus & Uterine Septoplasty & U2a Co v0 \\
\hline Case 8 & Primary Amenorrhoea & Mullerian Agenesis & Conservative; Follow up & U5 C4 V4 \\
\hline Case 9 & Post Menopausal Bleeding & Unicornuate Uterus & Hysterectomy & U4b Co vo \\
\hline Case 10 & Primary Infertility & Septate Uterus & Uterine Septoplasty & U2a Co vo \\
\hline Case 11 & Pain Abdomen & $\begin{array}{l}\text { Obstructed Uterus Bicornis } \\
\text { Bicollis with septate vagina }\end{array}$ & Vaginal Septoplasty & U3c C2 V2 \\
\hline \multicolumn{5}{|c|}{ Obstetric cases } \\
\hline Case & Clinical Picture & Anamoly & Management & $\begin{array}{l}\text { ESHRE } \\
\text { Classification }\end{array}$ \\
\hline Case 12 & Breech & Subseptate Uterus & LSCS & U2a Co vo \\
\hline Case 13 & Ruptured Ectopic Pregnancy & Bicornuate Uterus & Cornual Resection & U3b Co v0 \\
\hline Case 14 & Placenta Previa & Unicornuate Uterus & LSCS & U4b C 0 V0 \\
\hline Case 15 & Oblique Lie & Unicornuate Uterus & $\begin{array}{l}\text { Lower segment caesarean } \\
\text { section }\end{array}$ & U4b C 0 V0 \\
\hline Case 16 & Oblique Lie & Unicornuate Uterus & LSCS & U4b Co V0 \\
\hline Case 17 & Transverse Lie & $\begin{array}{l}\text { Unicornuate Uterus with left } \\
\text { rudimentary horn }\end{array}$ & Preterm Delivery & U4b C 0 V0 \\
\hline
\end{tabular}


unicornuate uterus with no horn was found with bilateral normal ovaries.

\section{Case 17}

A 28-yrs-old female $G_{2} P_{1} L_{0}$ with 8 months period of gestation presented with complaints of pain abdomen since 12 hours. She gave history of previous preterm vaginal delivery at 8 months of gestation, 2 years back. On examination she had a fundal height of 34 weeks with transverse lie and mild uterine contractions were present. Fetal heart rate was 140 beats per minute. Patient was taken up for caesarean section in view of transverse lie in labour. Per operatively right sided unicornuate uterus with left rudimentary horn with no cavity with normal ovaries was seen.

Table 1 summarizes the clinical picture, associated Mullerian anomaly and subsequent management of the respective cases.

\section{Discussion}

The series comprises of 17 cases of Mullerian anomalies, diagnosed through clinical history, physical examination, radiological scans or surgery. Out of the 17 cases, 11 cases presented with gynaecological problems and remaining 6 were patients with obstetrical complaints.

The most common age presentation in obstetric cases was 24-26 years and 14-17 years in gynaecology cases. In literature the average age at diagnosis of Mullerian anomalies is reported to be from $10-18$ years [4].

Primary amenorrhoea was the most common complaint among the gynaecological cases while others presented with primary infertility. Similar to the findings by Vyas, et al. who reported primary amenorrhea as the most common symptom in a study conducted in India in 2018 [5].

Amongst obstetrical cases, main problem encountered were ectopic pregnancy, recurrent pregnancy loss, abortion and preterm labour. Poor obstetric outcomes are mainly attributed to those anomalies which involve the uterus and include increased rate of recurrent pregnancy loss, pre-term delivery, malpresentations, fetal growth restriction and increased caesarean delivery rates [6].

In the present study the most common anomaly encountered in obstetric cases was unicornuate uterus, contrary to the findings by Raj, et al. who did an observational study of effect of Mullerian anomalies on pregnancy in 2019, and found that the most common anomaly complicating pregnancy was septate uterus (36.6\%) [7].

Amongst the gynaecological cases the most frequent diagnosis made was MRKH. Agarwal, et al. evaluated cases of Mullerian anomaly over a period of three years and discovered MRKH syndrome was the most common diagnosis for the cases which presented with primary amenorrhoea [8].

In the current study almost all patients were worked up for other anomalies, however only one patient was found to have associated renal anomaly. According to the work done by Li S, et al. [9], the association between renal and Mullerian agenesis is around 30\%. Treatment modalities in both obstetric and gynaecological cases were mostly individualized according to the case diagnosed.

A clear knowledge about the types, diagnosis, surgical management if any and the consequences of the Mullerian anomalies and its management is important.

Mullerian anomalies of obstructive nature are atypical and frequent in adolescence therefore strong clinical suspicion is imperative for making a proper diagnosis. Investigating modalities commonly used for diagnosis are USG, HSG, MRI, CT scan and IVP. HSG is the most common investigation whereas MRI continues to be the benchmark for accurate diagnosis of Mullerian anomalies. A thorough investigation of urinary tract should also be done, as solitary ectopic kidney could be mistakenly injured or excised during surgery. Frequently encountered upper urinary tract abnormalities include renal anomalies (20-30\%) such as a horseshoe or pelvic kidney or renal agenesis, duplication of the collecting system, and ectopic ureters. The priority in such cases should be fixation of obstructive symptoms and achievement of normal menstrual, sexual and reproductive functions. Psychological treatment and reconstructive surgery are the main stay of management. The female should also be made aware of the possibility of treatment failure and the counseling should focus on the severity of the malformation in question. On the contrary the anomalies which are diagnosed first time during pregnancy are usually found to be minor and management revolves around a favorable pregnancy outcome along with fixation of the anomaly where possible.

\section{Conflict of Interest}

None.

\section{Funding}

None.

\section{References}

1. Saravelos SH, Cocksedge KA, Li T-C (2008) Prevalence and diagnosis of congenital uterine anomalies in women with reproductive failure: A critical appraisal. Human $\mathrm{Re}$ production Update.

2. Grimbizis GF, Camus M, Tarlatzis BC, Bontis JN, Devroey $P$ (2001) Clinical implications of uterine malformations and hysteroscopic treatment results. Hum Reprod Update 7: $161-174$.

3. Grimbizis GF, Gordts S, Sardo AdS, Brucker S, Angelis C (2013) The ESHRE/ESGE consensus on the classification of female genital tract congenital anomalies. Hum Reprod 28: 2032-2044. 
4. Mueller GC, Hussain HK, Smith YR, Quint EH, Carlos RC, et al. (2007) Mullerian duct anomalies: Comparison of MRI diagnosis and clinical diagnosis. AJR Am J Roentgenol 189: 1294-1302.

5. Vyas RC, Moghariya AM, Shah SR, Parikh PM, Shelat PM (2019) Mullerian ductal anomalies and its outcome. Int J Reprod Contracept Obstet Gynecol 8: 440-444.

6. Miglani U, Laul P, Kadam VK, Miglani S (2019) Obstructive mullerian anamolies: A case series. Int J Reprod Contracept Obstet Gynecol 8: 2954-2958.
7. Raj N, Chavan NN (2019) An observational study of effect of Mullerian anomalies on pregnancy. Int J Reprod Contracept Obstet Gynecol 8: 1155-1161.

8. Agarwal M, Bhushan D, Agarwal N, Singh S (2019) The spectrum of müllerian anomalies presented in a tertiary care centre: Three-year experience. J Genit Syst Disord.

9. Li S, Qayyum A, Coakley FV, Hricak H (2000) Association of renal agenesis and mullerian duct anomalies. Journal of Computer Assisted Tomography 24: 829-834. 